Journal of

Accident and Emergency Medicine 1995 12, 296-297
Correspondence: John Ryan, Accident and Emergency Department, King's College Hospital, Denmark Hill, London SE5 9RS, UK

\title{
Insulin dependent diabetes mellitus and deliberate self-harm
}

\author{
J. RYAN, ${ }^{1}$ C.A. PEREZ-AVILA ${ }^{2} \&$ N. VAUGHAN ${ }^{3}$ \\ ${ }^{1}$ Accident and Emergency Department, King's College Hospital, London, UK, Departments of \\ ${ }^{2}$ Accident and Emergency and ${ }^{3}$ Medicine Royal Sussex County Hospital, Eastern Road, Brighton, UK
}

\section{SUMMARY}

Patients who deliberately harm themselves can present with a variety of disorders. The case is reported of a patient who deliberately self-harms by inducing hypoglycaemic episodes. This patient has placed great demands on the emergency services over the last 9 years. Early involvement by senior accident and emergency staff is advised.

Key words: diabetes mellitus, deliberate self-harm, hypoglycaemia

\section{INTRODUCTION}

Patients with diabetes often present to the accident and emergency (A\&E) department with hypoglycaemia. When resulting from insulin overdose, hypoglycaemia is usually accidental but it is well described as a method of suicide in patients with diabetes and health care workers. ${ }^{1,2}$ We report the case of a patient who presented to the emergency services over a period of years with recurrent episodes of hypoglycaemia and in whom deliberate self-harm is suspected.

\section{CASE HISTORY}

We reviewed the case notes of a 47-year-old woman with diabetes who has been attending the hospital for 9 years. The first available record is an out-patient entry from July 1985, when she was referred to the diabetic outpatients clinic by the A\&E team after two attendances with hypoglycaemia. Her attendances at the A\&E department have continued since then and have increased each year. Most of her presentations are with hypoglycaemia. Despite over 100 attendances to the A\&E department she has only been admitted on four occasions, including two admissions with hyperglycaemic ketoacidosis. She has attended the diabetic out-patients clinic a number of occasions, but has generally defaulted from the offered appointments. The emergency ambulance service has made hundreds of calls to her house, administering glucagon on many occasions with good effect. Her glycosylated haemoglobin remains within satisfactory limits, reflecting good control of her diabetes.

The patient has been diabetic since the age of 15 years and has a turbulent social history. She is separated from her husband and moved to this area to live with another man in 1985. Contact with her previous hospital revealed frequent presentations with hypoglycaemia.

Although she denies intentional overdosage of insulin, we have discounted the possibility of a medical explanation for her recurrent hypoglycaemic episodes. Her knowledge of diabetes is adequate, as would be expected after 30 years of the illness, and we feel that her hypoglycaemia is not due to ignorance of management. Insulin levels after a hypoglycaemic episode have been high and $\mathrm{C}$ reactive protein has been low, indicating that the insulin detected is of exogenous origin.

We have tried a number of measures to resolve the situation. A psychiatric consultation was arranged, however, she lied openly to the psychiatrist about her domestic circumstances. Detention under section was not advised. She declined further psychiatric help. The diabetic team manipulated her insulin type, dose and distribution to no avail. A district nurse who monitored her insulin administration and blood glucose levels for four days found no apparent insulin overdosage, but still an ambulance was required on three occasions during these 4 days to take her to 
J. Ryan et al.

hospital. On another occasion a nurse specializing in diabetes monitored her insulin dose using a pen device and found her technique to be adequate. Her boyfriend has been provided with glucagon to administer during hypoglycaemic attacks, but this has not reduced her attendance rate at the A\&E department.

\section{Discussion}

We report this case to highlight the possible consequences for both patient and medical staff when managing patients who have deliberately selfharmed by inducing hypoglycaemic attacks.

Over the last 9 years this patient has placed a huge demand on the emergency services, the A\&E department and the diabetic team. She requires immediate action on arrival at the A\&E department, often requiring intervention by senior medical and nursing staff in her resuscitation and because of difficulties with intravenous access.

This form of deliberate self-harm is extremely dangerous. This patient has been fortunate in that she has been found on most occasions when she is hypoglycaemic before she becomes unconscious. There is also a serious risk that she may sustain significant permanent neurological damage as repeated neuroglycopenia may have long-term consequences of intellectual impairment.

\section{REFERENCES}

1. Roberage R.J., Martin T.G. \& Delbridge T.R. (1993) Intentional massive insulin overdose: recognition and management. Annals of Emergency Medicine 22, 228-234.

2. Kaminer Y. \& Robbins D.R. (1988) Attempted suicide by insulin overdosage in adolescent girls with insulin-dependant diabetic adolescents. Paediatrics 81, 526-528. 